\title{
Fracture humerus during caesarean section: a case report
}

\author{
Rakesh Kumar' ${ }^{1}$ Rajlaxmi Mundhra ${ }^{2 *}$ \\ ${ }^{1}$ Department of Pediatrics, VCSGGIMS and R, Sriangar, Pauri Garhwal, Uttarakhand, India \\ ${ }^{2}$ Department of Obstetrics and Gynaecology, All India Institute of Medical Sciences, Rishikesh, Uttarakhand, India
}

Received: 16 April 2018

Accepted: 29 May 2018

\section{*Correspondence:}

Dr. Rajlaxmi Mundhra,

E-mail: Rmundhra54@yahoo.com

Copyright: $\odot$ the author(s), publisher and licensee Medip Academy. This is an open-access article distributed under the terms of the Creative Commons Attribution Non-Commercial License, which permits unrestricted non-commercial use, distribution, and reproduction in any medium, provided the original work is properly cited.

\begin{abstract}
Caesarean section is considered safer than vaginal delivery in risks involved for birth injury. Birth injury is more common in vaginal breech deliveries but are also encountered in caesarean section. Authors hereby report a case of long bone fracture in a neonate which occurred during caesarean section. The neonate presented with erb's palsy and wrist drop. Baby was admitted and was managed with a U slab (pop slab) with physiotherapy which was later replaced by arm body strapping. Obstetricians and Paediatricians should remain vigilant for the rare chance occurrence of birth injuries during caesarean section also so that cases are not missed and managed timely for prevention of disability and deformities later.
\end{abstract}

Keywords: Birth injury, Caesarean, Fracture, Humerus

\section{INTRODUCTION}

Birth related fractures are one of the known complications during labour and delivery.

The incidence and prevalence of these depends on many factors which may be maternal, foetal and resource related. Increase in caesarean rates have been associated with decrease in the incidence of birth injuries. ${ }^{1}$

Caesarean section though considered safer than vaginal delivery is not devoid of risks. In certain difficult cases neonate may suffer injury due to difficult extraction of baby and mechanics of delivery during caesarean section.

Many a times these injuries are difficult to explain and cause significant distress not only to the to the neonate but also to the family and obstetrician.

Obstetrician and paediatrician needs to be vigilant about the possibility of such type on injury for early detection of the same. Authors report such a case sustaining fracture of humerus during caesarean delivery.

\section{CASE REPORT}

A 28-year-old lady G2P1 at 36 weeks of gestation was referred to us with transverse lie with hand prolapsed. There was history of manipulation for delivery at the referring hospital. She was taken for emergency caesarean section. Ante natal period was normal. There was no history of metabolic bone disease, osteogenesis imperfecta, diabetes mellitus and syphilis in parents or family.

Baby was stuck in the pelvis and the caesarean incision needed to be extended in an inverted $T$ shape. A crackling sound was heard during disengagement of hand from pelvis. Child cried immediately after birth and apgar score was 8 and 9 at 1 and 5 minutes respectively. Erb's palsy (Figure 1) and wrist drop (Figure 2) was present during examination with limited movement of right arm, crepitus was present in mid arm. Rest of the physical and systemic examination was normal. Baby was shifted to SNCU for observation and $\mathrm{x}$ ray of shoulder with long bones was done. Digital x ray showed spiral fracture of shaft of humerus (Figure 3). The hand was immobilized 
with U slab (pop slab) by orthopedician which was later replaced by arm body strap on day 7 . Physiotherapy in the form of exercise of shoulder, elbow and wrist was advised by physiotherapist. Baby was discharged on day 8 and was advised for follow up in OPD at 3 weeks but he lost to follow up.

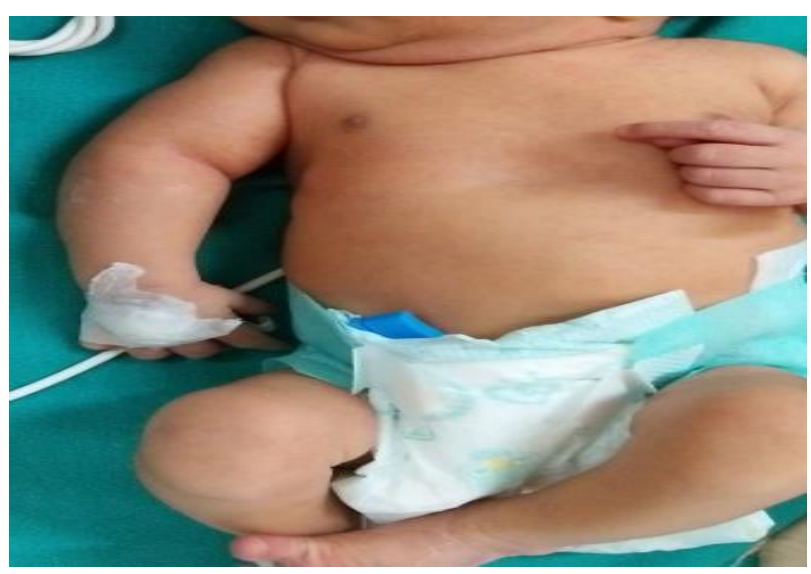

Figure 1: Erb's palsy.

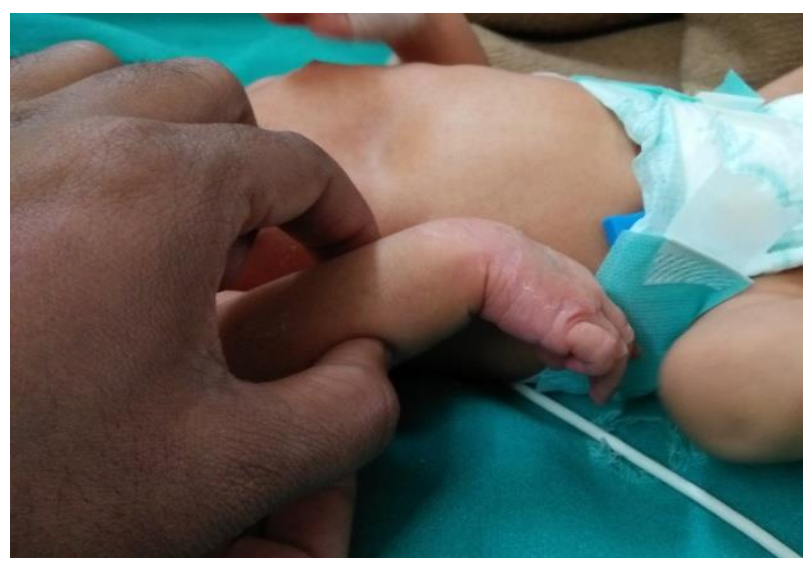

Figure 2: Wrist drop

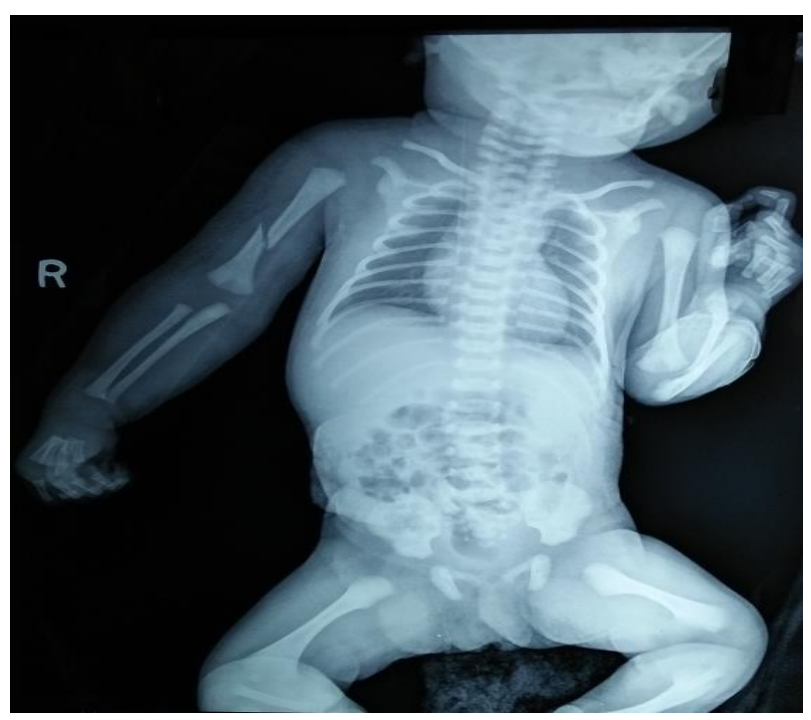

Figure 3: Digital $x$ ray at D1 of life

\section{DISCUSSION}

Long bone fractures are unpredictable and sometimes unavoidable complication of birth. In study by Bhatt Clavicular fracture was found to be commonest followed by humerus. ${ }^{2}$ Difficulty encountered in the delivery of the shoulders in cephalic deliveries and of extended arms in breech deliveries often produces such fractures. Humeral fractures are often of the greenstick type, although complete fracture with overriding bones may occur. ${ }^{3}$ An estimated three-quarters of all long-bone fractures during birth are ascribed to vaginal breech deliveries. ${ }^{4}$ Madsen reported an incidence of $0.75 \%$ for all birth-related long bone fractures including fractures of the clavicle. ${ }^{5}$ Although the clavicle has been reported as the commonest bone to fracture after birth trauma during caesarian delivery, other long bone fractures such as femur, humerus, and monteggia fracture dislocation have been described. ${ }^{6-8}$

The risk factors of birth injury include obstetric manoeuvres during delivery especially LSCS, prolonged labour, prematurity, macrosomia, breech presentation, shoulder dystocia and forceps assisted delivery. ${ }^{9,10}$ In study done by Nasab et al, $42.9 \%$ of the bone fractures occurred without any predisposing factors which makes it one of the overlooked complication which should be kept in mind and be informed to the parents beforehand. ${ }^{11}$

In study carried out by Puza et al showed that the increase in cesarean section of $4 \%$ lead to a significant decrease in the rate of major birth trauma. ${ }^{12}$ Birth injuries are a rare but still a known complication which may occur during caesarean deliveries. Caesarian section avoids the risk of head entrapment, but long bone trauma can still occur. ${ }^{13}$ Toker et al while reporting a case series on femoral fracture after caesarean section stated that caesarean section increases the risk of long bone fractures. ${ }^{14}$

Fetal injuries complicate $1.1 \%$ of cesarean deliveries. The frequency of fetal injury at cesarean delivery varies with the indication for surgery as well as with the duration of the skin incision-to-delivery interval and the type of uterine incision. ${ }^{15}$

Neonatal humeral fractures can occur in the proximal or distal epiphysis or in the diaphysis. Madsen found that the most common fractures were transverse mid-shaft ones, followed by fractures of the proximal and distal epiphysis. In his study a significant number of fractures occurred in babies born via cesarean section, which is considered to be safer than vaginal delivery.

Nearly one-half $(48.0 \%)$ of the patients with birth fractures were diagnosed after a delay of 3 to 7 days in the series reported by $\mathrm{Al}-$ Habdan. Treatment options vary and range from simple chest bandages and von Rosen splints to U slab. ${ }^{16}$ It is important to remember that the fracture union may look quite unsatisfactory initially, 
but 40-50-degree moulding can occur in two years' time and parents may be reassured of the same.

\section{CONCLUSION}

To conclude it can be stated that birth injuries can occur in LSCS. Adequate care is to be taken during extraction of child and during traction of limbs even in caesarean section. It is prudent on the part of operating surgeon and paediatrician to initiate appropriate investigations and management on slightest suspicion so that future deformities and disabilities can be prevented.

Funding: No funding sources Conflict of interest: None declared

Ethical approval: Not required

\section{REFERENCES}

1. Jain NJ, Kruse LK, Demissie K, Khandelwal M. Impact of mode of delivery on neonatal complications: trends between 1997 and 2005. The J Mat- Fetal Neonatal Med. 2009;22(6):491-500.

2. Bhat BV, Kumar A, Oumachigui A. Bone injuries during delivery. The Indian J Ped. 1994;61(4):401-5.

3. Williams JW. Prior Cesarean Delivery. Cunningham FG, Leveno KJ, Bloom SL, Spong CY, Dashe JS, Hoffman BL Diseases and Injuries of the Fetus and Newborn.eds, Williams obstetrics. $24^{\text {th }}$ ed. New York:McGraw-Hill;2014:637-52.

4. Salonen IS, Uusitalo R. Birth injuries: incidence and predisposing factors. J Ped Surg. 1990;45(03):133-5.

5. Madsen ET. Fractures of the extremities in the newborn. Acta Obstet Gynecol Scand. 1955;34(1):41-74.

6. Al-Habdan I. Birth-related fractures of long bones. Indian J Pediatr. 2003;70:959-60.
7. Cebesoy FB, Cebesoy O, Incebiyik A. Bilateral femur fracture in a newborn: an extreme complication of cesarean delivery. Arch Gynecol Obstet. 2009;279:73-4

8. Jones GP, Seguin J, Shiels WE $2^{\text {nd }}$. Salter-Harris II fracture of the proximal humerus in a preterm infant. Amer J Perinatol. 2003;5:249-53.

9. Ogbemudia AO, Ogbemudia EJ. Emergency caesarean delivery in prolonged obstructed labour as risk factor for obstetric fractures-a case series. Afr J Reprod Health. 2012;16(3):119-22.

10. Nadas S, Reinberg O. Obstetric fractures. Eur J Pediatr Surg. 1992;2:165-8.

11. Nasab SAM, Vaziri S, Arti HR, Najafi R. Incidence and associated risk factors of birth fractures in the newborns. Pak J Med Sci. 2011;27(1):142-4

12. Puza S, Roth N, Macones GA, Mennuti MT, Morgan MA. Does cesarean section decrease the incidence of major birth trauma?. J Perinatol: Official J California Perinatal Assoc. 1998;18(1):9-12.

13. Vasa R, Kim MR. Fracture of the femur at cesarean section: case report and review of literature. Amer $\mathbf{J}$ Perinatol. 1990;7:46-8.

14. Toker A, Perry H, Cohen E. Cesarean section and the risk of fractured femur. IMAJ. 2009;11:416-8.

15. Alexander JM1, Leveno KJ, Hauth J, Landon MB, Thom E, Spong CY, et al Fetal injury associated with cesarean delivery. Obstet Gynecol. 2006;108(4):88590.

16. Campbell RH. Problem injuries in unique conditions of the musculoskeletal system. In: Rockwood CA, Wilkies KE, Beaty $\mathrm{JH}$, editors $4^{\text {th }}$ ed. Fracture in children. 1996;3:274-5.

Cite this article as: Kumar R, Mundhra R. Fracture humerus during caesarean section: a case report. Int $\mathrm{J}$ Reprod Contracept Obstet Gynecol 2018;7:2965-7. 